\title{
Reseña de Estudiu de la transición llingüistica na zona Eo-Navia, Asturies. ETLEN, dirigido por Ramón d'Andrés
}

\author{
José EnriQue Gargallo Gil \\ Universitat de Barcelona I \\ Institut d'Estudis Catalans \\ gargallo@ub.edu \\ ORCID iD: 0000-0002-8874-0323
}

Ramón d'Andrés Díaz (dir.), Fernando Álvarez-Balbuena García, Xosé Miguel Suárez Fernández y Miguel Rodríguez Monteavaro (2017): Estudiu de la transición llingüistica na zona Eo-Navia, Asturies. ETLEN. Atles llingüisticu. Dialectográficu - Horiométricu Dialectométricu, Uviéu: Trabe [Io83 pp.]. ISBN: 978-84-8053-892-3.

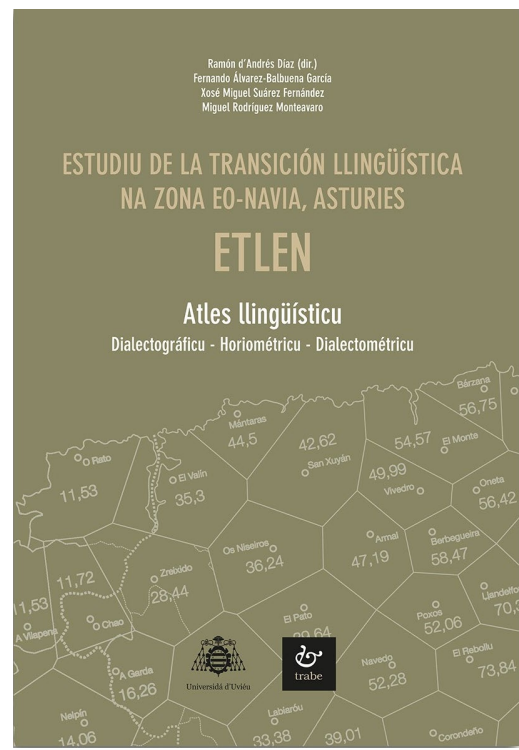


La cantidá masiva d'información que l'ETLEN ofrez, y tamién la novedá del so enfoque, suponen un avance non solo na conocencia concreta d'esta frontera llingüística, sinón tamién na conocencia teórica y xeneral de les fronteres llingüístiques. Nesti sen, el métodu utilizáu nel ETLEN ye perfectamente aplicable a otres zones de transición asemeyaes, como podríen ser por exemplu la del aragonés y catalán nel leste de la provincia de Huesca, la del occitanu y el francés nel Creissent, o la del castellanu y el gallegoportugués nel norte del Uruguái. (P. 22)

$\mathrm{E}$ L párrafo con el que los autores concluyen la "Introducción" (pp. 9-22) de este monumental trabajo, cuya versión impresa sobrepasa el millar de páginas, destaca la relevancia de la obra como modelo para la investigación de áreas de frontera difusa o gradual en la vieja Romania: así, la frontera catalano-aragonesa o el Creissent que media entre los tipos galorromances septentrional (oíl, francés) y meridional (occitano); o incluso para el estudio de un área de contacto y mezcla (entre castellano y portugués; quizá mejor nombrarlo portugués en este caso, y no gallegoportugués) como el fronterizo del norte de Uruguay.

Lo monumental del trabajo se acredita ya desde los créditos previos a los "Agradecimientos" (p. 7) y a la mencionada "Introducción". El pormenor sobre autoría, colaboradores en las distintas fases del proyecto y referencias sobre años (de 2000 a 20I3) y entes de financiación, con la especificación de los respectivos códigos, resulta bien elocuente. Asimismo, la "Introducción” por sí sola prefigura la magnitud y la cualidad del estudio que es objeto de esta reseña. Es minuciosa la presentación de la zona Eo-Navia, con este y otros nombres, de los que no hay uno que sea popular ${ }^{1}$; el encuadre demográfico y económico; la adscripción geolingüística de la zona y los glotónimos preferidos por unos u otros, sin faltar la mención al gallego-asturiano ideado por Dámaso Alonso (p. Io); las isoglosas principales manejadas tradicionalmente (diptongación o adiptongación de $\breve{\mathrm{E}}$ y $\breve{O}$ latinas, pérdida o mantenimiento de -L-, suerte de las geminadas -LL- y -NN-), que suponen una caracterización muy exigua (en cambio, el ETLEN, en su propósito de obtener una descripción más exhaustiva de la zona, implica centenares de isoglosas, a partir de 368 fenómenos lingüísticos objeto de atención, ejemplificados con 53 I ítems). Además, se repasan los estudios previos sobre la zona, así como las miradas sobre esta de la tradición dialectológica asturiana, hispánica y románica a lo largo de más de un siglo (desde finales del XIX), y el debate actual. Los objetivos y principios generales dan pie a señalar las tres perspectivas o enfoques del ETLEN; como anuncia el título: I) el dialectográfico (identificable con los atlas lingüísticos clásicos); 2) el horiométrico —en este radica la mayor originalidad del estudio-, que establece la adscripción de tres tipos geodife-

\footnotetext{
${ }^{1}$ El orden invertido de los ríos de referencia, Navia-Eo, es comprensible que no se haya elegido para el título, que habría resultado en un acrónimo impronunciable: ETLNE.
} 
renciales: occidental, oriental y axial (nótese la evitación de las designaciones paralelas pero connotadas de gallegoportugués, asturleonés y eonaviego); y 3) el dialectométrico, basado en procedimientos matemático-estadísticos.

El atlas asume la división de la península ibérica en diversos geotipos romances (catalán, aragonés, castellano, asturleonés y gallegoportugués), así como la existencia de fronteras entre ellos, que en el norte peninsular se presentan como transiciones lingüísticas, zonas de transición o continuos fronterizos (pp. I4-15). Y en torno a una de tales áreas de transición, entre los geotipos gallegoportugués y asturleonés, se articula la investigación del ETLEN.

El cuestionario específico del atlas se ciñe a los 368 fenómenos geodiferenciales, relacionados con uno o varios "ítems" ("palabres o espresiones concretes recoyíes como respuestes y qu'exemplifiquen cada fenómenu nun mapa independiente", p. I 5), que suman el total de 53 I, y tienen que ver con geovariantes representadas en los dos principales geotipos concurrentes (occidental y oriental), así como en el axial o central. Todo ello se divide en tres bloques: fonética y fonología, morfosintaxis no verbal y morfosintaxis verbal. Por otra parte, se ha prescindido de fenómenos referidos al léxico por razones metodológicas ${ }^{2}$.

La red de lugares encuestados, de una densidad media de uno por cada $100 \mathrm{~km}^{2}$, contiene cuarenta puntos, repartidos mayoritariamente entre el Eo y el Navia, en continuidad con dos espacios limítrofes, a manera de franjas, del asturiano occidental y del gallego oriental (la de este trasciende la raya administrativa de Asturias y alcanza a cuatro puntos de la provincia de Lugo). Los informantes se escogieron según los cánones de la dialectología tradicional (mayores de 65 años, nacidos y residentes en el lugar, no muy instruidos ni viajados, en buenas condiciones mentales, capaces de verbalizar y pronunciar adecuadamente). Se ofrece la lista completa de encuestados y encuestadores, y también una muestra visual de informantes, rostros de la tierra, retratados en media docena de fotos humanísimas entre las páginas i 9 y 20. Ahora bien, echo en falta la especificación del procedimiento de encuesta: ¿pregunta directa?, ¿indirecta?, ¿conversación guiada?

El caso es que el material logrado se traduce en los correspondientes cuadernos de campo y unas 240 horas de grabación, y el tratamiento de toda esta cosecha de datos se canaliza a través de los tres enfoques aludidos: el tradicional o dialectográfico, el horiométrico (procedimiento cuantitativo o estadístico) y el dialectométrico (procedimiento matemático-estadístico). Para los dos primeros se ha utilizado el pro-

\footnotetext{
${ }^{2}$ La vastedad del léxico obligaría a una selección aleatoria que condicionaría de manera asimismo aleatoria los resultados. Solo la indagación de un área semántica concreta parece viable en este tipo de estudio (Cf. Andrés 20r6).
} 
grama Cartografía Dialectal (CartoDial), creado y registrado por el equipo investigador del proyecto ETLEN; para el tercero, el programa Visual DialectoMetry (VDM), creado por el equipo de dialectometría de la Universidad de Salzburgo y adaptado al proyecto ETLEN.

Los tres enfoques en cuestión originan las tres secciones que conforman el núcleo del libro: "Sección dialectográfica" (pp. 23-930), que constituye una especie de atlas lingüístico a la vieja usanza, en que alternan síntesis textuales y mapas; "Sección horiométrica” (pp. 93 I-987); “ “Sección dialectométrica” (pp. 99 I-I 043); estas dos últimas, más breves, tienen carácter interpretativo y sumario, tras haber pasado la cosecha dialectal por el cedazo metodológico de los correspondientes programas de tratamiento de datos.

El análisis dialectográfico que precede a la primera y principal sección (pp. 25-29) establece las pautas que guían la presentación textual de cada fenómeno geodiferencial (una página por fenómeno) y la plasmación de los datos en los mapas (también un mapa por página). Y cada página de presentación textual se encabeza con una combinación alfanumérica mediante una letra mayúscula inicial $(\mathrm{F}=$ fonética y fonología; $\mathrm{N}=$ [morfología] nominal; $\mathrm{V}=$ [morfología] verbal) más un número, seguida del pertinente epígrafe, en que se afinan minuciosamente los condicionantes etimológicos y contextuales de cada fenómeno: desde "F I. Conservación o diptongación de les vocales /E/ y / / / tóniques llatines" (p. 3 I) hasta "V95. Usu de suxuntivu o d'indicativu nel verbu poder como verbu principal n'oraciones de sentíu conxetural” (p. 929). Tras la combinación identificativa y el epígrafe, se relacionan de manera sistemática el ítem o los ítems correspondientes en asturiano normativo (por ejemplo, "puerta", “vieyu”, para Fi; “pue que venga”, para V95), la adscripción geotipológica de las variantes (occidentales, orientales y, eventualmente, axiales; también, oportunamente, el eco de algunos fenómenos en los dominios gallegoportugués y asturleonés), el esquema horiométrico y, en algunos casos, observaciones adicionales a final de página. En cuanto a los mapas, ofrecen mayoritariamente respuestas en transcripción, y ocasionalmente con símbolos.

Esta parte del atlas, que contiene 53 I mapas dialectográficos, constituye un tesoro de información geolectal cuidadosamente presentada y explicada mediante las respectivas síntesis textuales. Muestra de ello es alguno de los aspectos que me han llamado la atención y que señalo aquí. Por ejemplo, en relación al adverbio entós (N92), se maneja una gran cantidad de variantes: ocho para el tipo occidental, once para el oriental. También con respecto a la tercera persona del singular del pretérito indefinido de poner (V53), con una veintena de variantes tenidas en cuenta, y repartidas entre los tipos occidental, axial y oriental. Por otro lado, bajo "F 54. Conservación o perda de -L- intervocálica llatina”, es interesante constatar que la extensión 
del mantenimiento de dicha consonante (rasgo oriental) es diferente para los dos ítems elegidos, "palu” y "caliente" (p. I 59). Bajo "F73. Terminación tónica llatina INU: resultáu -in, -inu frente a -iño" se constata un tratamiento fonético distinto del general en uno de entre los varios ítems de un solo punto de encuesta: "En Guímara (Forniella) dizse vecín, pequeñin, molín, toucin, pero camíu” (p. 21 I). Es asimismo reveladora la observación sobre el yeísmo que asoma en algunos informantes, que alternaban la indistinción yeísta con la distinción entre $/ K / \mathrm{y} / \mathrm{j} /$ (p. I $8 \mathrm{I}$ ). Además, la confrontación con los datos de obras previas justifica oportunos comentarios; así, a propósito de "N47. Caltenimientu o perda de la $-s$ final de los pronomes átonos nos y vos nes xuntures con pronomes átonos de complementu directu de $3 .{ }^{\text {er }}$ persona", se indica lo siguiente: "Los casos de mantenimientu de $-s$ que detecta l'ALGa na marina de Cuaña y Tapia nun se confirmaron nes nuestres encuestes” (p. 4Io). Constituyen igualmente un índice de calidad y de claridad los esquemas evolutivos en torno a la desinencia de la $3 .{ }^{\mathrm{a}}$ persona del singular de los verbos de la $2 .{ }^{\mathrm{a}}$ conjugación (V25: "perdió", "bebió", p. 764) y de la tercera (V26: "partió", "siguió", p. 766).

Pero todo reseñador está obligado a señalar también aspectos que considera mejorables. Y yo, que estoy más familiarizado con esta sección dialectográfica tradicional que con las otras dos, me permitiré algunas observaciones en este sentido. Acaso la formulación de "hiatu producíu pola perda d'una consonante non nasal" (p. 94) referida al ítem "chimenea", galicismo peninsular tomado del francés cheminée, no sea la más adecuada en referencia a un fenómeno de lenición extrema que viene ya dado desde la lengua de origen a partir del latín CAMINATA. Asimismo, a propósito de "F85. Caltenimientu o perda (con ulteriores efectos) de -N- intervocálica na terminación llatina -ĀNES” (p. 239), no parecen del mismo rango etimológico los ítems "canes" y "folgazanes", ya que aquel hereda el latín CANES, mientras que este otro deriva de holgar en época romance (cf. Corominas I980-I99I: s. v. holgar). En "F90. Simplificación o palatalización de -NN- y -MN- intervocáliques llatines" (pp. 254256), fenómeno para el que se han seleccionado los ítems "cabańa" y "pequeñu", este segundo no resulta el más adecuado como posible heredero del grupo -MN- (según Corominas 1980-199I, pequeño sería una voz expresiva cuyo étimo contiene la terminación -INNU). En cambio, se ajusta inequívocamente a esa condición etimológica otro tipo léxico como es dañu (< DAMNU), seguramente preferible. Por otra parte, no me queda claro el epígrafe "F91. Formación o non del grupu romance -M'N->-m-" (p. 257), que sugiere el tipo oriental con -mbr-allumbrar (tal como en castellano alumbrar), por más que ninguno de los cuarenta puntos de estudio para los ítems "fema" y "allumar" (mapas I 37 y I38) registre este resultado. En "F I09. Consonante implosiva -/s/ o - / / / delantre de /p/o /k/: los casos de raspiar 
y caspa" (p. 304), se echa en falta un ítem adecuado a la consonante /k/, pues "razpiar" y "cazpia" solo se ajustan a la primera de las opciones, /p/. Por fin, a propósito de "V5 r. Forma de la $3 \cdot{ }^{\text {er }}$ persona del singular del pretéritu indefiníu de los verbos tener y tar" (p. 836), no aparecen los resultados de tener ni el mapa correspondiente; solo los de tar (ítem "tuvo" y mapa 482).

El neologismo horiometría, creado por el equipo del ETLEN, es definido ('midimientu de la frontera xeolectal') y justificado etimológicamente ("del griegu hórion 'frontera, llende' y métron 'midida”) al inicio de la "Sección horiométrica" (p. 933). La adscripción de los distintos rasgos geodiferenciales "a un espaciu o bien occidental (grosso modo gallegoportugués), o bien oriental (grosso modo asturllionés), o bien axial (grosso modo eonaviegu), o bien común (occidental y oriental al empar)" (ib.), se lleva a cabo conforme a la tipología lingüística y la distribución geolectal de dichos rasgos. Siguiendo un criterio glotológico, estrictamente "intralingüístico", se prefiere la terminología clasificatoria neutra y de pura referencia geográfica a las denominaciones subyacentes del tipo de gallegu, asturianu, gallego-asturianu.

En esta misma sección horiométrica, bajo el apartado de "Análisis horiométricu" (pp. 933-949), se establecen los criterios "metrizadores" que han de posibilitar un tratamiento estadístico fiable de datos y se analizan casos diversos. Asimismo, se clasifican los mapas horiométricos resultantes según el tipo de representación gráfica (circulares y poligonales) y según el alcance del corpus (totales o parciales). Los circulares marcan en distintos colores (azul: adscripción oriental; rojo: oriental; amarillo: axial; verde: común) los porcentajes sobre círculos asignados a cada uno de los 40 puntos de encuesta (véase la muestra de las pp. 952-958). Los poligonales son de cuatro tipos: de referencia occidental, de referencia oriental, de referencia axial y de referencia occidental/oriental; en ellos los polígonos correspondientes a cada punto reciben una escala cromática más o menos intensa conforme a su porcentaje en relación con las distintas referencias (véase la muestra de las pp. 960-987). Ambas muestras combinan mapas circulares o poligonales con los de alcance de corpus total o parcial.

La "Sección dialectométrica" culmina el estudio. En ella se explicita el seguimiento de las pautas de la Escuela de Dialectometría de Salzburgo, dirigida por el Prof. Hans Goebl, cuyo programa Visual Dialectometry (VDM) sirve de guía al ETLEN a partir de una adaptación realizada en el año 2009. La dialectometrización de los datos, convertidos en unidades de cómputo estadístico (taxats), posibilita análisis cuantitativos diversos, a partir de las distintas fases operativas (matriz de datos, taxación, índices de semejanza/distancia, matriz de semejanza/distancia), tal como se precisa bajo el epígrafe de "Metodoloxía dialectométrica" y se expone en las pp. 992-998. Los índices de semejanza/distancia, a la luz de algoritmos varios, dan 
lugar a tipos diversos de análisis y mapas: sinópticos o de semejanza, que pueden ser a su vez de punto de referencia (en la zona de estudio, uno frente a los 39 restantes) o integrales; interpuntuales (isoglóticos o de rayos); así como correlativos y dendrográficos. La amplia variedad de posibles mapas se ilustra, con profusión de colores que marcan diferencias bien visibles, en la muestra final de las pp. I007-I043.

Las "Conclusiones" (pp. I045-I047) parecen corroborar la percepción tradicional sobre esta área romance de frontera gradual:

Na parte más occidental d'Asturies constátase la esistencia d'un área de transición ente los dominios gallegoportugués y asturllionés, siendo la zona Eo-Navia l'aguada occidental d'esa frontera, desque nella falaríase - d'acordies col consensu cuasi unánime dientro la dialectoloxía hispánica y románica一 un gallegoportugués de transición al asturllionés. (P. 1045)

Entre estos dos dominios romances, gallegoportugués y asturleonés, que muchos preferirán identificar respectivamente con los nombres más precisos de gallego y asturiano, media una frontera lingüística cuyo trazo resulta aproximado al que suponía la tradición de la dialectología científica, "pero non igual dafechu" (como se indica en la p. 1046). Y vale la pena transcribir un par de observaciones cruciales de estas últimas páginas, en referencia al espacio central del estudio y a la frontera lingüística:

Esti espaciu central pue garrar, según los casos, la forma d'una faza media qu'enancha pela parte septentrional, o d'un triángulu embrocáu na parte norte del mapa, dexando asina al sur una zona de contactu directu ente les faces llaterales [...]. (PP. 1046-1047)

En llinies xenerales pue dicise que la frontera llingüística que se descubre tien una parte septentrional abondo más gradual que la parte meridional, muncho más abrupta, según dexen ver los mapes sinópticos, isoglóticos y correlativos. (P. 1047)

Sigue a las conclusiones una cuantiosa "Bibliografía" de referencia (pp. I049I06I), relativa en su mayor parte a la "Introducción”. El "Índiz de formes llingüístiques" (pp. I063-I074), con remisión al número de mapa de la sección dialectográfica, y el "Índiz" general del libro (pp. I075-1083) completan esta obra monumental, de la que cabe elogiar la elección del asturiano como lengua de redacción, así como un esmero formal prácticamente impecable ${ }^{3}$.

\footnotetext{
${ }^{3}$ Dejo constancia, en nota, de las escasas anomalías que he detectado en mi lectura: la marca acentual de azúis ("namás se rexistra en Valdeferreiros (Ibias)" [p. 177]) no se corresponde con la del mapa 88 de la página siguiente ("azuís"); falta el punto y aparte del segundo párrafo de la p. 502; lapsus de occidental por oriental en "Les formes diptongaes siente, miente constátense na banda occidental de la zona d'estudiu” (p. 710, en referencia a los mapas 390 y $39 \mathrm{I}$ de las dos páginas siguientes); en la combinación alfanumérica del fenómeno "V.53" [sic] media el punto entre la letra y el número, cuando debería ir a continuación ("V53."); falta la cursiva de la letra final de "variabilidá" (p. 933, segunda línea del segundo párrafo); falla la concordancia de número en "l'aplicación de diferentes matrices y algoritmos producen" (p. 999). En cuanto a las referencias bibliográficas, la mención parentética de "(ALDC, J. Veny)" (p. 99I) debiera incluir también a la otra codirectora del atlas, Lídia Pons i Griera. Sí aparece, en cambio, en la "Bibliografía" final ("VENY, Joan \& Lídia PONS", p. I06I), si bien el segundo ańo de referencia (200I-20го) no corresponde al de publicación de los últimos volúmenes, que han ido apareciendo a lo largo de la segunda década del siglo (el VIII es de 20I6). Falta el signo
} 
En suma, el método empleado en el estudio de esta frontera lingüística proporciona una cantidad y una cualidad de datos que retratan con enorme nitidez esta área de frontera difusa o gradual entre los dos geotipos principales del noroeste peninsular. Dicho método de estudio podría muy bien extenderse a otras áreas dialectales vecinas: de la frontera lingüística hacia el sur, del Principado de Asturias o del dominio asturleonés. El equipo del proyecto ETLEN demuestra con su Estudiu estar de sobra capacitado para acometer nuevas empresas de investigación dialectográfica, horiométrica y dialectométrica.

\section{REFERENCIAS BIBLIOGRÁFICAS}

ANDRÉS, Ramón de (2016): "Variación dialectal en el léxico de la fauna marina de Asturias: una indagación dialectométrica”, en Nikola Vuletić, Xosé Afonso Álvarez Pérez y José Enrique Gargallo Gil (eds.), Mari romanzi, mari di contato. Lessico e paremiologia, Zadar: Sveučilište u Zadru [Universidad de Zadar], pp. I3-40.

Corominas, Joan (I980-I99I): Diccionario crítico etimológico castellano e hispánico (colab. José Antonio Pascual), Madrid: Gredos. 6 vols. 